\title{
O SOFISMA DA SUSTENTABILIDADE URBANA
}

\author{
the sophistry of urban sustainability
}

Pacelli Henrique Martins Teodoro*

\begin{abstract}
Resumo
No final do século XX, a sustentabilidade urbana surge no íntimo das funções sociais da cidade, com o discurso de torná-la mais eficaz. Contudo, quando se pensa no mundo contemporâneo e prospectivo, os resultados dessa promessa podem ser considerados inadmissíveis. Desse modo, o presente artigo teve como finalidade contestar a expressão sustentabilidade urbana, por meio da pontuação de seus sofismas. Em sua contextualização temporo-espacial, nas escalas global e local, as temáticas do desenvolvimento e da sustentabilidade foram questionadas com base no cenário ocidental, desde a década de 1970. No panorama das desordens globais, evidenciou-se o comando supremo da dimensão econômica, no que dizem na política, na vida sócio-cultural e no meio natural, enquanto no da produção local, comprovou-se um espaço reestruturado, com fragmentações e segregações urbanas, sem manifestações de cidadania e manejos conscientes de recursos. Assim, as realidades apresentadas não condizem e nem se adéquam, em um futuro próximo, às premissas da sustentabilidade urbana, levando a considerá-la como uma idéia pérfida, formulada com o propósito para induzir outrem a erro.
\end{abstract}

Palavras-chave: Sustentabilidade urbana, Sofisma, Desordens globais, Produção do espaço urbano.

\begin{abstract}
In the late twentieth century, the urban sustainability arises in the depths of social functions of the city, with the speech to make it more effective. However, when one considers the contemporary and prospective world, the results of that promise can be deemed inadmissible. Thus, this paper aimed to challenge the term urban sustainability, through the scores of their sophistries. On temporal-spatial context in the global and local scales, the issues of the development and sustainability have been questioned on the basis of occidental scenario, since the 1970s. In the panorama of the global disorders, showed the supreme command of the economic dimension in the others, politics, socio-cultural life and natural environment, while in the local production, proved a restructured space, with fragmentations and segregations urban, without symptoms of citizenship and aware managements of resources. Thus, the realities presented do not match and fall into line, in the near future, the assumptions of urban sustainability, leading to consider it as an insidious idea, formulated with the purpose to induce others into error
\end{abstract}

Key words: Urban sustainability, Sophistry, Global disorders, Urban space production.

\section{Resumen}

En el final del siglo XX, la sostenibilidad urbana surge en lo íntimo de las funciones sociales de la ciudad, con el discurso para hacerla más eficaz. Sin embargo, cuando se considera el mundo contemporáneo y futuro, los resultados de esa promesa pueden ser considerados inadmisibles. Por lo tanto, este artículo tiene como objetivo impugnar la expresión sostenibilidad urbana, a través de las puntuaciones de sus sofismas. En su contexto temporo-espacial, en las escalas global y local, las cuestiones del desarrollo y la sostenibilidad fueron cuestionadas con base en el escenario occidental, desde la década de 1970. En el panorama de los trastornos mundiales, reveló un mando supremo de la dimensión económica en los otros, política, vida socio-cultural y medio ambiente natural, mientras que en la producción local, demostró un espacio reestructurado, con fragmentaciones y segregaciones urbanas, sin manifestaciones de ciudadanía y gestiones conscientes de recursos. Por lo tanto, las realidades presentadas no coinciden y corresponden, en un futuro próximo, los supuestos de la sostenibilidad urbana, que lleva a considerarlo como una idea insidiosa, formulada con el fin de inducir al error.

Palabras-clave: Sostenibilidad urbana, Sofisma, Trastornos mundiales, Producción del espacio urbano.

(*) Doutorando do Programa de Pós-graduação em Geografia da Universidade Estadual Paulista - Rua Roberto Simonsen, 305 - CEP: 19.060-900, Presidente Prudente (SP) - Brasil, Tel.: (+ 55 18) 32295388 - phmteodoro@hotmail.com 


\section{INTRODUÇÃO}

A partir de 1970, o mundo passou a confrontar-se com mudanças e contradições multidimensionais, em mais variadas escalas. A procura para conciliar desenvolvimento-ambiente desembocou-se no ecodesenvolvimento, a primeira proposta voltada ao crescimento econômico e os usos de recursos naturais. Posteriormente, o debate internacional cunhou o desenvolvimento sustentável, uma tentativa para harmonizar os sistemas econômico, social e ambiental, sob a égide da esfera política.

Ainda com incertezas e sem consensos, o desenvolvimento sustentável irrigou suas propostas para várias áreas de interesse social, fato que não poderia ser diferente para as questões que envolviam a cidade. A produção do espaço urbano tenta ganhar uma nova aliada: a sustentabilidade urbana, a qual surge no íntimo das funções sociais da cidade, com promessa de torná-la mais durável.

Entretanto, determinados agentes sociais, preponderantes na produção da cidade, têm se apropriado da sustentabilidade como mero artifício discursivo, para produzir e promover o espaço por meio do pensamento único, instaurado conforme seus interesses emblemáticos, normalmente com pretensões de inserção multiescalar na disputa por capitais. Para tanto, eles buscam sua legitimação objetiva em discursos da sustentabilidade urbana, repletos de ideologias socialmente hegemônicas, em promoção da cidade sustentável.

Quando o olhar se volta às reais situações em que se encontra o mundo, o adjetivo sustentável perde a credibilidade, já que suas propostas não são compatíveis e, muito menos, viáveis para a contínua vigência do sistema capitalista. Por isso, parte-se da hipótese que as realidades sócio-espaciais contemporâneas, tanto globais, quanto locais fornecem argumentos verdadeiros e suficientes sobre o caráter falacioso das ofertas da sustentabilidade, termo tão disseminado e aclamado na sociedade, pelos mais distintos agentes.

Desta maneira, o presente estudo teve como objetivo contestar a sustentabilidade urbana, a partir da pontuação dos sofismas presentes nessa expressão, com fundamentos em sua contextualização temporo-espacial, nas diferentes escalas geográficas.

Este artigo faz parte da pesquisa "Sustentabilidade urbana: sofisma, polissemia e utopia", nível mestrado (2008-10) e também com fomento da FAPESP, indicada para o doutorado direto (2008-12), pelo Programa de Pós-graduação em Geografia, da FCT-UNESP. O estudo foi indicado pela banca do Exame Geral de Qualificação, composta pela Profa. Dra. Maria Encarnação Beltrão Sposito e pelo Prof. Dr. João Lima Sant'Anna Neto, e, após o parecer positivo de um avaliador externo, o Programa aprovou a indicação, sem ressalvas.

\section{A CIDADE SUSTENTÁVEL}

Sem tardar, após a II Guerra Mundial (1939-1945), surgiram as primeiras discussões sobre novos modos para reconstruir as economias de países atingidos e fundamentar, ao lado do resguardo da paz em países descolonizados, a filosofia da Organização das Nações Unidas (ONU). Além do mais, os países periféricos se viam ainda mais desiguais, mesmo logo após o rápido crescimento econômico-industrial que tinham perpassado, durante a década de 1950, diferentemente do que ocorrera com os países centrais. Em vista disso, o crescimento perde crédito e o desenvolvimento sobressai-se, com total ênfase na agenda internacional.

No ano de 1972, a primeira Conferência das Nações Unidas sobre o Meio Ambiente, a Cúpula da Terra I, foi realizada na cidade de Estocolmo. Sob a coordenação do secretário-geral Maurice F. Strong, os perigos ambientais globais, na visão dos países centrais, como a relação entre o uso de clorofluorcarbonos (CFC) e a destruição da camada de ozônio, foram os destaques e os alvos de debates, fato que marcou um relevante ponto na história da política ambiental internacional, com o carro-chefe ecodesenvolvimento. A partir de tal evento, a dimensão ambiental ganhou grande realce sob demais dimensões, sejam econômica, política, social, entre outras, todavia, nem sempre de maneira ética, muitas vezes em proveito próprio, outras em culpabilidades pelos desastres. 
Em 1987, o desenvolvimento sustentável passou a ser intensamente propagado entre os discursos, os programas e as promessas. Presidida pela diplomata norueguesa Gro Harlem Brundtland, a Comissão Mundial sobre Meio Ambiente e Desenvolvimento (CMMAD) difundiu a expressão por meio do relatório "Nosso futuro comum", o qual aponta a incompatibilidade entre o desenvolvimento pretendido e os atuais padrões de produção-consumo, assim como apresenta uma lista de ações estatais e metas internacionais, sob a égide de agentes de diferentes instituições multilaterais.

Ainda que tenha sido adotada no debate por meio de ambientalistas, a sustentabilidade possui tantas facetas quanto o próprio desenvolvimento. Originalmente, tal substantivo incorporou-se a esse adjetivo a fim de ser "[...] aquele que atende às necessidades do presente sem comprometer a possibilidade de as gerações futuras atenderem a suas próprias necessidades." (CMMAD, 1991, p. 46).

Cinco anos mais tarde, no dia 3 a 14 de junho, na cidade do Rio de Janeiro, foi organizada a segunda Conferência das Nações Unidas sobre Meio Ambiente e Desenvolvimento (CNUMAD), a Cúpula da Terra II, também popularmente conhecida como ECO-92 e Rio-92. Anteriormente propagado, o desenvolvimento sustentável consagra-se, nesse momento, por meio de uma ampla conscientização de que os países desenvolvidos eram majoritariamente responsáveis por certos danos ao meio ambiente, enquanto os países subdesenvolvidos necessitavam receber mais apoio financeiro e tecnológico, bem como serem ouvidos na agenda internacional.

Centrada em três convenções (as mudanças climáticas, a biodiversidade e, em menor interesse, a desertificação), a Rio-92 propiciou a redação de alguns documentos oficiais, dentre dos quais se destaca a Agenda 21. Documentada em quarenta capítulos, por 179 países, a referida agenda é um programa de ação que visa promover um novo padrão de desenvolvimento, em escala planetária, para o século XXI, conciliando métodos de proteção ambiental, de justiça social e de eficiência econômica (Figura 1).



Figura 1 - Matriz do desenvolvimento sustentável. Elaboração e layout: TEODORO, 2010. 
Seja no fórum Rio+5, de 13 a 19 de março de 1997, novamente no Rio de Janeiro, seja na cúpula Rio+10, de 26 de agosto a 4 de setembro de 2002, em Johanesburgo, a avaliação dos avanços e dos obstáculos da Rio-92 comprovou-se que grande maioria dos países não vinha cumprindo com os acordos estabelecidos, o que deixava evidente as deficiências discursivas e os impasses intergovernamentais. A mais, as nações interpretaram os documentos de maneiras distintas, conforme os próprios interesses, afinal, "atrelado ao substantivo desenvolvimento, o adjetivo sustentável tornou ainda mais espessa a cortina de fumaça que envolve o uso abusivo e a disputa ideológica pelo significado real dessas duas palavras." (LEROY et al., 2003, p. 16).

Deslocar um paradigma, até então, e tentar literalmente desenvolvê-lo em um espaço urbano, ao mesmo tempo fragmentado e articulado, reflexo e condicionante social, conjunto de símbolos e campo de lutas (CORRÊA, 2002), não constitui uma tarefa fácil, nem um processo conciliável entre todos. Para tanto, do desenvolvimento sustentável à sustentabilidade urbana, da abrangência à especificidade, é preciso aprofundar a discussão entre a teoria e a prática.

A administração municipal possui como meta o desenvolvimento urbano, por meio da plena ordenação das funções sociais da cidade. Com o objetivo de garantir o bem-estar dos habitantes, tais funções classificam-se em três grandes grupos: as funções urbanísticas, as funções de cidadania e as funções de gestão, regidas politicamente de acordo com as diretrizes gerais da constituição.

Em 1933, na cidade de Atenas, os membros do IV Congresso Internacional de Arquitetura Moderna (CIAM) definiram, basicamente, quatro funções urbanísticas: habitação, recreação, trabalho e circulação. Apesar de haver propostas para adição de demais funções, como a Carta de Aalborg (1994), pela European Cities \& Towns Towards Sustainability, e a própria Nova Carta de Atenas (1998; 2003), pela European Council of Town Planners, nota-se que a política legislativa e do planejamento têm se pautado no refúgio familiar, no contato social, nas atividades produtivas e na mobilidade como os principais requisitos do urbanismo moderno, durante boa parte do século passado e ainda do presente.

Previstas legalmente e asseguradas pelo Estado, em mais diversos níveis, as funções de cidadania pleiteiam que todo ser humano possui o direito à proteção social, a qual desdobra na educação, na saúde e na segurança. Basicamente, essas funções constituem-se em direitos sociais, garantidos na legislação.

As funções de gestão pública possuem a finalidade de administrar o território, a serviço de garantir a eficácia no manejo de recursos e de efetivar os direitos civis, de maneira coletiva e democrática. O planejamento é a palavra-chave dessa questão, o qual é um processo contínuo de onde se encontra e aonde se quer chegar, ou seja, é a percepção da realidade, a avaliação dos rumos e a elaboração do referencial desejado, alguns com prognósticos de resultados. O ordenamento territorial e a distribuição de serviços públicos são importantes exemplos que são exercidos pelo planejamento.

Dentre as funções urbanas, a sustentabilidade surge no íntimo da gestão, com promessa de tornar a cidade mais durável, ágil e eficiente. A cidade sustentável é reconhecida por sua autossuficiência produtiva, em relação ao uso consciente de recursos naturais, com o (re)aproveito máximo de matérias e energias. Contudo, embora a sustentabilidade possua a teoria de ser economicamente viável, ambientalmente correto e socialmente justo, é necessário que se reflita sobre sua prática.

Para Acselrad (2009), a noção de sustentável associa-se ao debate sobre o desenvolvimento das cidades nas rearticulações políticas, pelas quais certos agentes procuram dar legitimidade a suas perspectivas, com a compatibilidade das mesmas aos propósitos da durabilidade do desenvolvimento, em consenso com os princípios da Agenda 21. Para isso, no campo da política, observa-se a crescente entrada ambiental no debate urbano, bem como o movimento oposto, o urbano no debate ambiental. A mais, nota-se, também, o recurso de associar a sustentabilidade a estratégias de execução da metáfora cidade-empresa, a qual possui alguns supostos atributos atrativos de investimentos, no contexto da competição interurbana e global.

Acselrad (2004) ainda garante que os agentes hegemônicos utilizam a sustentabilidade para representar a identidade simbólica da cidade, promovendo o novo modo de regulação do capital, o 
qual se identifica por alguns traços: as condições de reprodução do capital são menos coordenadas pelo Estado central e os poderes locais assumem papel proativo nas estratégias de desenvolvimento econômico; desenvolve-se uma competição interurbana, pela oferta de possibilidades de consumo de lugar, pela atração de turistas e de projetos/eventos culturais; desenvolve-se competição interurbana, pela capacidade de controlar funções de comando financeiro e comunicacional; os processos econômicos passam a subordinar as políticas sociais e de emprego; e as novas condições de governo dos processos urbanos passam a envolver também atores não governamentais, privados e semipúblicos. Ao reproduzir as cidades por meio de mecanismos da crise urbana, tal regulação apropria-se das contradições espaciais da acumulação flexível como seu principal motor.

Desta maneira, a concepção preponderante de sustentabilidade urbana consiste na duração da cidade, particularmente em sua materialidade técnica de estoques-fluxos necessários à acumulação. A durabilidade encontra-se no ajuste ecológico dos fluxos urbanos, na chamada modernização ecológica das cidades, pela qual a insustentabilidade se daria naquela cidade ameaçada pela queda da produtividade física, utilitária do meio para o capital; "busca-se, aqui, economizar a cidade, adotar tecnologias poupadoras de espaço, matéria e energia e reciclar materiais." (ACSELRAD, 2007, p. 4).

$\mathrm{Na}$ tentativa de ser sustentável, cada cidade se apega a um enfoque territorial, a fim de desenvolvê-lo. Na conjuntura européia, Emelianoff (2003) identificou seis apropriações básicas: 1) a mobilização comunitária, a comunidade como legitimação de sociabilidade e de apaziguamento das tensões interétnicas ou geracionais (Reino Unido e mundo anglo-saxão); 2) ecotécnicas, ecocertificados e eco-orçamentos, meios de etiquetagem ecológica de produtos, com foco técnico-científico (Alemanha, Áustria, Dinamarca, Suíça e Países-Baixos); 3) os modos de vida, locais e globais, apóiam-se na responsabilização individual, com alto nível de sensibilização ecológica (Norte da Europa, em particular a Escandinávia); 4) a planificação voluntarista, onde o espaço é limitado, dá-se preferência à mistura funcional, proliferando a cidade compacta (países renanos); 5) a renovação patrimonial, uma reabilitação sócio-ecológica de construções antigas, em conjunto a seu tecido social (ex-República Democrática Alemã); 6) e a qualidade de vida, pela qual a cidade se transforme em uma hospitalidade multidimensional, um espaço de reencontros (Sul da Europa e França).

Por conseguinte, os agentes sociais apropriam-se da sustentabilidade urbana a partir de diversos sentidos, por meio de artifícios discursivos, encontrados em agendas e programas governamentais. Cada apropriação simboliza a interpretação conceitual do que é ser sustentável, a qual está, de forma geral, em concórdia aos interesses de determinados agentes, um grupo minoritário que regula e rege o sistema, para sua contínua acumulação flexível de capitais.

Para confirmar tal afirmação, panoramas de como se encontram os cenários global e local identificam alguns dos chamados impasses temporo-espaciais, isto é, determinados obstáculos que dificultam o alcance e pleno êxito das promessas sustentáveis. Em outros termos, entraves da ordem global e local, no tempo e espaço, que fundamentam o caráter falacioso da sustentabilidade, seus sofismas, e confirmam que essa nada mais é do que a politização da natureza, a nova feição específica da geopolítica contemporânea (BECKER, 2008).

\section{A SUSTENTABILIDADE E SEUS SOFISMAS}

Por sua importância na representação abstrata dos fenômenos, segundo Castro (2008), o estudo recorre-se à escala geográfica, no primeiro instante. A problemática operacional da escala está em sua libertação fortemente cartográfica, pois à medida que o tamanho muda, o conteúdo e o sentido também mudam. Desse modo, atenta-se que a observação e concepção do fenômeno adquirem características particulares com a mudança escalar, em especial quando esse pode assumir formas sócio-espaciais mais complexas.

Conhecer os processos e as dinâmicas globais e locais, da chamada ordem "glocal", é indispensável para compreender o desafio imposto pela sustentabilidade urbana, sejam os que a favo- 
recem ou dificultam. E esse conhecimento advém, obrigatoriamente, de procedimentos de retorno às condições históricas presentes no Ocidente, a partir de 1970.

\section{Panorama das desordens globais}

Contextualizar o mundo contemporâneo, temporal e espacialmente, é deparar-se com uma "des-ordem" mundial (HAESBAERT; PORTO-GONÇALVES, 2006), pois enquanto muros e símbolos Leste-Oeste sucumbem-se, muitos outros novos Norte-Sul materializam-se, no mesmo instante. Se antes o mundo era dividido em colonizador/colonizado, homem livre/escravo (sem considerar as contradições étnicas e de classes), agora é pelo binômio desenvolvido/subdesenvolvido, logrando com a ideologia da ascensão social, pela qual se poderia passar de um estado ao outro, como entendem Acselrad e Leroy (1999).

A desordem econômica permite compreender melhor as desordens política, sócio-cultural e ambiental, dado que o jogo de poder mundial é regido pelo grande capital, pelas corporações transnacionais e pelos organismos internacionais, sob o comando do Banco Mundial e do Fundo Monetário Internacional (FMI). A reestruturação econômica tem desregulamentado os mercados, propiciados pelas normas do capitalismo neoliberal e sua lógica globalizante. Em decorrências, há crescentes choques de civilizações e hibridismo cultural, assim como a privação, comercialização e degradação dos recursos naturais.

No modo de produção capitalista, vemos a produção extensiva, em grande escala, a aceleração de ritmos, a homogeneização de espaços sociais e naturais. Na verdade, o desenvolvimento tem se constituído num processo de redução da complexidade. Reduz-se a complexidade do tecido social e dos ecossistemas; transforma-se todo mundo em assalariado ou em miserável; e a natureza em monoculturas. Assim, pretende-se reduzir a complexidade do tecido urbano, visualizando as cidades como plataformas de produção, reprodução e expansão do capitalismo, e todo morador urbano, como um simples consumidor. (ACSELRAD; LEROY, 1999, p. 12).

Considerada o ápice do processo de internacionalização do mundo capitalista, com fundamentos no modo de produção e no processo civilizatório de alcance mundial, a globalização é o produto das ações que garantem a emergência de um mercado dito global, o qual se apóia no atual sistema técnico, o informacional (SANTOS, 1996; 2002). Essa etapa histórica, do meio geográfico, diferencia-se pelo forte entrelaçamento entre a ciência e a técnica ("tecnociência"), aliadas à informação.

A marcha transitória do fordismo à acumulação flexível (HARVEY, 2003) constituiu-se em um grande passo para a construção do mundo global. A produção e o consumo em massa, que se sintetizam em um novo tipo de sociedade modernista, racionalizada, democrática e populista, cederam espaço para a reestruturação produtiva e a revolução tecnológica, com desdobramentos na flexibilidade dos processos e mercados de trabalho, assim como dos produtos e padrões de consumo. Tal reestruturação possibilita elevados ganhos de produtividade (modo de produção just-in-time), maior eficiência administrativa e menores custos ao grande capital, adaptando-o à flexibilidade.

Para sua acumulação, o capitalismo necessita e utiliza-se de certas situações e estratégias, respectivamente. Harvey (2004) traçou duas proposições: o ímpeto de acelerar o tempo de giro do capital, apressando seu ritmo de circulação, e revolucionar os horizontes temporais de desenvolvimento; e o sentimento de eliminar todas as barreiras espaciais, por meio da produção de um espaço fixo, a fim de acomodar sua acumulação. Esse processo suscita a aceleração dos ritmos de vida, a chamada compressão do tempo-espaço (HARVEY, 2003), a qual tem impactado, com desorientação e disrupção, as práticas político-econômicas, o equilíbrio do poder de classe e a vida social e cultural - consequências da rapidez temporal do vínculo entre a troca e o consumo.

Por isto, é preciso indagar quem vivencia a compressão do tempo-espaço, em conjunção com seus benefícios e malefícios (MASSEY, 2000). Afinal, essa compressão não vem acontecendo para todos, nem para todas suas esferas de atividade, de forma justa e com equidade. 
Passível a críticas, Bauman (1999) propôs a idéia de divisão de tempo-espaço entre o Primeiro e o Segundo Mundo. Os habitantes dos países desenvolvidos vivem no tempo, em um presente perpétuo, com o espaço transposto de qualquer distância - as pessoas têm o tempo todo tomado, sem tempo; enquanto os dos países subdesenvolvidos, ao contrário, vivem no espaço, qualificado como pesado, resistente, intocável, que prende o tempo e o mantém fora de controle - o tempo é redundante, inútil e vazio, nada acontece.

Neste rumo reflexivo, adentra-se na geometria do poder, como denominou Massey (2000), a qual se refere às formas do posicionamento de grupos sociais e indivíduos perante os fluxos e as interconexões. $\mathrm{O}$ distinto relacionamento entre os agentes e suas mobilidades distingue-se em quem se responsabiliza, inicia, exclui ou aprisiona pelo movimento.

Deste modo, afirma-se que há diferenciação social altamente complexa na compressão do tempo-espaço. E tal distribuição das pessoas não se limita, apenas, em sua capacidade de movimento, mas também, na mobilidade e no controle da minoria sobre a maioria, à parte dos processos. Essa compressão, de alguns grupos dominantes, pode aluir o poder dos demais.

A cultura contemporânea também se modifica em paralelo à globalização, tornando-se uma cultura mundial. Essa alude a novas maneiras do indivíduo povoar e viver o espaço, o qual se encontra impregnado de artifícios para seu aprisionamento (ORTIZ, 1994).

A cultura mundial reflete, principalmente na etapa do capitalismo tardio posterior à II Guerra Mundial, a maneira e capacidade de pessoas em consumir bens, traduzindo-se em uma característica cultura de consumo. Nesse sentido, a sociedade de consumo é produzida por economias de prestígio, as quais produzem bens escassos, que demandam tempo, dinheiro e saber, para classificar o grau de distinção do próprio portador. Para suas efetivações, esses bens são comercializados por meio de imagens, signos e símbolos de sonhos, desejos e fantasias, com a finalidade de proporcionar prazer a si mesmo, de maneira narcísica, e não aos outros.

Já na globalização da natureza, a problemática ambiental ganha maiores consistências e dilemas no sistema neoliberal. As implicâncias do poder mundial no meio natural podem ser exemplificadas com base na dívida ecológica, a qual consiste em uma busca de recursos monetários em moeda não emitida, criando um enorme dever contra a natureza e os povos excluídos ambientalmente. A mais, a natureza possui a funcionalidade como mercadorias.

Para Santos (1996), nos dias atuais, a sociedade depara com uma profunda crise ambiental, impulsionada pelos tipos de objetos técnicos, assim como pelas motivações de seu uso. Em busca do motor único, a mais-valia global, o impulso produtivo torna-se indiferente às realidades ambientais, perturbando-as e desencadeando a capacidade local de controlar as forças atuantes. Assim, a crise ecológica proporciona maior vulnerabilidade ao homem, acompanhada, em paralelo, com o esvaziamento político local.

Portanto, de maneira intrínseca, a presente ordem global não abandona seu caráter perverso, impulsionado pelo exclusivo estado político nos usos técnicos, como bem refletiu Santos (2002). Sustentáculos do sistema ideológico contemporâneo, as tiranias do dinheiro e da informação, intimamente relacionadas, impõem-se a maioria dos homens como uma globalização perversa. Fonte de novos totalitarismos, essa confere o sentimento de competitividade, devido à produção em larga escala e o consumo exacerbado, facilmente aceitos pela mistura de valores e opiniões que provoca na vida social e pessoal.

\section{Panorama da produção local}

De acordo com o que foi explanado e discutido, até o presente momento, as pressões globais possuem grande parcela de influências e transformações locais. Assim, os estudos sobre a produção dos espaços urbanos e, também, rurais necessitam de uma visão atenta na relação global-local. Com fundamentos nessa concepção, a sociedade contemporânea carece, conforme a célebre frase, "pensar globalmente, agir localmente". 
Segundo os dados populacionais, da United Nations (UN, 2009), as áreas urbanas concentravam, em 1950, 29\% da população mundial, atingindo $37 \%$, em $1975,46,5 \%$, em 2000 , e 50,5\%, em 2010, com o tendente crescimento para 56,5\%, em 2025, e 68,5\%, em 2050. Na escala nacional, essas reuniam, em 1950, 36\% da população brasileira, alcançando $61 \%$, em 1975, 81\%, em 2000, e 86,5\%, em 2010, com o tendente aumento para 90,5\%, em 2025, e 93,5\%, em 2050.

Com base nestes dados estatísticos, afirma-se que a organização do espaço mundial manifesta-se, cada vez mais, no papel hegemônico da cidade. Pode-se considerar o século XX como o da urbanização, enquanto o XXI, o da cidade.

A cidade é produzida pelas complexas ações dos agentes sociais, os quais a (re)organiza, espacialmente, via incorporação de novas áreas; densificação do uso do solo; deterioração de certas áreas; renovação urbana; e relocação diferenciada da infraestrutura e mudança, coercitiva ou não, do conteúdo socioeconômico de determinadas porções do espaço, segundo Corrêa (2002).

Com fundamento nas Obras de Harvey (1980) e Corrêa (2002), os agentes podem ser sintetizados em três grandes grupos: a esfera pública, a esfera privada e a sociedade civil. O Estado representa a esfera pública, à medida que desempenha suas funções de tributador, legislador, empreendedor, fiscalizador e prestador de serviços. Já a privada é composta pelos proprietários fundiários, incorporadores, construtores, corretores e financiadores. Enquanto isso, os diversos grupos sociais, compostos pela sociedade organizada (identidades e ordens), pelas associações de bairro e pelos movimentos sociais, pela maçonaria e pelos excluídos, constituem a sociedade civil.

Lefebvre (1969) já salientava para o fato de que não existe uma marcha única ou unitária da reflexão urbanística, mas sim, tendências referenciáveis, como: o urbanismo dos homens de boa vontade; o urbanismo dos administradores ligados ao setor público; e o urbanismo dos promotores de venda. A mais, um agente pode encontrar-se entrelaçado em mais de uma tendência, como o Estado e os promotores imobiliários, particularmente na figura do agente incorporador, que somam como o principal eixo responsável pela produção do espaço urbano. A esfera pública desempenha, direta ou indiretamente, funções de agentes da esfera privada, por meio da organização do espaço urbano, via regulação do uso e da ocupação do solo.

Sendo a cidade uma imensa concentração de gente exercendo as mais diferentes atividades, é lógico que o solo urbano seja disputado por inúmeros usos. Esta disputa se pauta pelas regras do jogo capitalista, que se fundamenta na propriedade privada do solo, a qual - por isso e só por isso - proporciona renda e, em conseqüência, é assemelhada ao capital. (SINGER, 1980, p. 77).

Entende-se que o espaço intraurbano estrutura-se por meio do paradigma do conflito, a partir da proposição de Farret (1985). Esse paradigma se ampara nas idéias de desequilíbrio, funcionamento imperfeito do mercado, interesses e conflitos sociais; em outros termos, a estruturação do espaço se dá pela oferta, a qual seria regida, em vez de pelos consumidores individuais, pelo mercado imobiliário, dominado pelos interesses de grupos hegemônicos, e pelo Estado, como um agente ativo - é uma questão de poder.

Deste modo, o complexo e contraditório espaço urbano é produzido e consumido pelos agentes sociais, de diversos segmentos, por meio de suas diferentes práticas. Na presente concepção teórica, as mesmas são caracterizadas como práticas sócio-espaciais, remetendo-se à relação entre a sociedade e o espaço; uma sociedade só torna-se concreta por meio de seu espaço, assim como o espaço só é inteligível por meio da sociedade, ou seja, não há separação entre a sociedade e o espaço, ambos se interagem (SANTOS, 1996).

Segundo Harvey (2003), fundamentado em Lefebvre (1991), a sociedade vive, percebe e imagina o espaço pelas práticas de acessibilidade e distanciamento; de apropriação e uso; de domínio e controle; e de produção. Em situação de dependência de uma das demais, as práticas espaciais são eficientes a partir do momento em que se entrelaçam com a vida social e sua estrutura de relações sociais. No capitalismo, essas práticas ficam imbuídas de significados particulares ao capital, as 
quais assumem "[...] sentidos sob relações sociais específicas de classe, de gênero, de comunidade, de etnicidade ou de raça, e são 'usadas' e 'trabalhadas' no curso da ação social.” (HARVEY, 2003, p. 204).

Situada na Geografia pós-moderna, segundo Soja (1993), a atual reestruturação da cidade foi propiciada a partir da reestruturação produtiva e marcada, ao mesmo tempo, pela reestruturação espacial, temporal e social contemporânea. Em sentido mais amplo, o conceito de reestruturação transmite a noção de ruptura e mudança em direção a uma ordem e configuração significamente diferentes da vida social, econômica e política, evocando uma combinação sequencial de desmoronamento e reconstrução, de desconstrução e tentativa de reconstituição.

Deste modo, entende-se o termo reestruturação como novos usos, funções e formas da cidade, com significativas mudanças nos modos de vida - uma complexa redefinição sócio-espacial (CARLOS, 2004). Por isso, os espaços vêm passando por muitas mudanças em seu processo de urbanização, em especial em suas formas e funções, favorecendo a formação de uma cidade dispersa (tecido morfológico), acompanhada por uma urbanização difusa (aspectos processuais).

Com o fenômeno da expansão territorial, a tradicional e segregada estrutura urbana centro-periferia tornou-se mais dispersa e difusa, configurando-se por meio de fragmentos urbanos, como a presença adicional de um centro novo, subcentros ou núcleos secundários, shopping centers e condomínios autossegregados; uma total descontinuidade territorial, mas integrada espacialmente, mesmo que seja de uma maneira seletiva (SPOSITO, 2004). Essa redefinição iniciou-se, sobretudo, no final do século XX, a partir da década de setenta e oitenta, e define a divisão econômica do espaço.

Por meio das práticas sócio-espaciais, cada vez mais dispersas, a atual reestruturação da cidade capitalista promove tanto diferenciações, quanto concentrações em seu fragmentado tecido morfológico, juntamente a suas exigências funcionais, que propiciam a segregação sócio-espacial. Tais processos definem a divisão social do espaço.

A segregação - tanto social, quanto espacial - é uma característica importante das cidades. As regras que organizam o espaço são basicamente padrões de diferenciação social e de separação. Essas regras variam cultural e historicamente, revelam os princípios que estruturam a vida pública e indicam como os grupos sociais se inter-relacionam no espaço da cidade. (CALDEIRA, 2000, p. 211).

Lojkine (1981) diferencia três tipos de segregação urbana: 1) uma oposição entre centro-periferia; 2) uma separação crescente das zonas de moradia de camadas sociais mais privilegiadas com as populares; 3 ) e um esfacelamento generalizado das funções urbanas, disseminadas em zonas distintas e, cada vez mais, especializadas.

Nos dias atuais, em um espaço urbano estruturadamente disperso e segregado, os moradores de menor renda ficam relegados a procurarem lugares a baixos custos e, geralmente, com ineficiências na prestação de serviços urbanos. Esses lugares localizam-se distantes do centro, dificuldade que se complica com o problemático transporte coletivo.

Tal impasse coloca as ações dos especuladores privados em jogo, visto que quando o poder público adota ou expande os serviços urbanos em uma zona precária, há tendência de valorização antecipada de seus imóveis pelas especulações imobiliárias, podendo ocorrer o deslocamento de antigos e pobres moradores para uma nova área problemática e a atração de outros novos, favorecidos economicamente. Essa realidade que não contempla aqueles que deveriam ser beneficiados e prolonga, viciosamente, a resolução do dilema.

Com todas estas particularidades, as cidades contemporâneas também são espaços de inseguranças socialmente concebidas e incubadas (BAUMAN, 2007), as quais voltam as suas características antigas e medievais, quando as muralhas, os fossos e as paliçadas simbolizavam a divisa entre nós e eles, ordem e selvageria, paz e guerra. Ao trocar um quinhão de segurança por um quinhão de liberdade, o homem vê a necessidade de se proteger de seu semelhante (apenas fisiologicamente), em prol da autossegregação em condomínios e, em decorrência, do afastamento da vizinhança e 
do resto da cidade. Desse modo, os atuais espaços urbanos têm sido associados mais ao perigo à proteção.

Diante aos fatos retratados, uma importante mudança ocorre na funcionalidade existencial dos espaços públicos e, sucessivamente, nas manifestações da cidadania. O recuo da cidadania corresponde, paralelamente, a um recuo do espaço público, a qual se diferencia daquela idéia fundadora dos primeiros anos da cidade moderna. De acordo com Gomes (2002), quatro processos são característicos do recuo dos espaços públicos: a apropriação privada crescente dos espaços comuns; a progressão das identidades territoriais; o emuralhamento da vida social; e o crescimento das ilhas utópicas.

Por fim, além desta problemática, há, também, problemas ambientais no espaço urbano, pois, segundo Porto-Gonçalves (2006, p. 192), "é grande o impacto ambiental provocado pelo aumento da concentração de população em alguns pontos do espaço geográfico, seja em cidades, seja em periferias.". Diversos problemas ambientais podem ser relacionados à urbanização do espaço, sintetizados, normalmente, nos movimentos de massa; nas ravinas e voçorocas; nas inundações e nos alagamentos; nas ilhas de calor; na poluição do ar; nos resíduos sólidos; na contaminação de cursos d'água e lençóis freáticos; nas mudanças na drenagem natural; nos desmatamentos; na extinção de espécies; entre muitos outros - alguns estudados por Guerra e Cunha (2005).

\section{CONSIDERAÇÕES FINAIS}

Desde as propostas desenvolvimentistas e o acréscimo de um qualificativo a sua cápsula conceitual, determinados agentes lucram com os discursos da sustentabilidade, no espaço urbano, apropriando-se de sentidos diversos. Normalmente, a cidade é produzida por meio do pensamento único, do ambiente único, que exige sua inserção competitiva no disputado mercado internacionalizado, por via da modernização ecológica, em promoção do urbanismo de resultados, o urbanismo just-in-time de mercado (ACSELRAD, 2009).

No panorama das desordens globais, traduzidas nas dimensões econômica, política, social, ambiental e cultural, o cenário mundial é comandado pelos mercados globais, devido às desregulamentações e normas providas da reestruturação produtiva, na fase da acumulação flexível. A compressão do tempo-espaço incita os choques de civilizações, desorientando as práticas políticas, os poderes de classes e a vida sócio-cultural. A mais-valia global priva, comercializa e degrada os recursos naturais, transformando-os em mercadorias para a minoria.

No panorama da presente produção local, o espaço encontra-se em intenso ritmo de urbanização, com o Estado e o agente incorporador como os principais responsáveis por suas dinâmicas e seus processos. Por meio das práticas sócio-espaciais, tais agentes regem a reestruturação da cidade, com ênfase no paradigma do conflito, em fomento de novos fragmentos urbanos, na divisão econômica do espaço, e da segregação urbana, na divisão social do espaço. Como espaços de inseguranças, as cidades contemporâneas são conhecidas pela ausência de manifestações da cidadania, com inúmeros problemas ambientais urbanos.

Assim, fortemente influenciada com os rumos globais, a realidade local apresentada não condiz e nem se adéqua às premissas do desenvolvimento e da sustentabilidade, que presumem espaços com equilíbrios entre os fatores econômicos, a vida social e o meio natural, com tempos que respeitam os ritmos de todos.

Já com visão no futuro, a tecnologia tem impactado as formas espaciais e as funções da cidade contemporânea, segundo Mitchell (2002), a qual corrobora com o surgimento de outra vida urbana, baseada na "urbanidade on-line". A produção em massa, a repetição e a padronização, características da era industrial, abrem, nesse momento, caminho para a inteligência, da era da informática, criando uma cidade enxuta e ecológica (lean and green). Com propósitos sustentáveis, tal cidade seria baseada na desmaterialização (ao invés de construções físicas, equipamentos virtuais); na 
economia de recursos (substituição da viagem física de bens e de pessoas para a viagem pela telecomunicação); na personalização em massa (distribuir, automaticamente, somente bens e serviços necessários em determinados contextos); na operação inteligente (implantações de alta tecnologia em aparelhos e sistemas que distribuem recursos esgotáveis); e na transformação sutil (passagem do presente para o futuro exposto por rota não destrutiva e incremental).

No entanto, Castells (1999) afirma que há importante face na relação mútua entre a nova tecnologia de informação e os processos de transformação social: o layout da forma urbana transforma-se na "cidade informacional", não em um padrão único, universal, mas sim, com características que dependem de contextos históricos, territoriais e institucionais; em outras palavras, mesmo com diferentes processos sociais, ainda assim se obterá uma cidade fragmentada e segregada, com ausências de direitos e justiças.

Logo, quando se pensa na sustentabilidade urbana, em atento aos atuais (e, até mesmo, os futuros) impasses temporo-espaciais, é possível considerá-la como um sofisma, pois parece ser uma proposta aparentemente válida, mas sem real conclusão, o que pode supor uma idéia pérfida, uma logração. O discurso da sustentabilidade parte de premissas tidas verdadeiras, contudo, os resultados são inadmissíveis, quando se pensa no mundo contemporâneo e prospectivo. Portanto, é um argumento falso, formulado com o propósito para induzir outrem a erro, uma verdadeira falácia.

Por outro lado, em desvio à normatividade e com fundamentos críticos, Teodoro (2010) entende a sustentabilidade urbana como um processo democrático, por meio da gestão participativa, fundamentada nas identidades comunitárias, com a finalidade de conceber a cidade como território por excelência do exercício de direitos, justo de oportunidades e acessível funcionalmente - um espaço emanado do e para o povo. Afinal, o desenvolvimento deve garantir a liberdade positiva de escolha e a efetivação de todos os direitos humanos, sempre apoiado na democracia (SEN, 1999).

Neste caso, Acselrad (2004) afirma que o adentro da sustentabilidade significa a exigência de um modelo alternativo de legitimação da diversidade social, no espaço urbano, que afirme novo ritmo das diferentes formas culturais de relação com a base material das sociedades, em reconhecimento da pluralidade existente na apropriação de territórios. Em um mundo onde o capital e a política devem ser reestruturados (SMITH, 1988), o principal alvo volta-se às extensas massas que há séculos nunca foram a real prioridade em quaisquer estratégias, projetos e ações sociais.

Portanto, o espaço urbano capitalista carece de propostas e práticas inovadoras, de acordo com suas complexidades e contrariedades glocais, orientadas para o planejamento e a construção de sociedades mais democráticas. Enfim, conforme Brand e Thomas (2005, p. 2), "making cities sustainable is now a major aim and claim of most cities in the world.".

\section{REFERÊNCIA BIBLIOGRÁFICA}

ACSELRAD, H. Desregulamentação, contradições espaciais e sustentabilidade urbana. Revista Paranaense de Desenvolvimento, n. 107, p. 25-38, jul./dez. 2004.

ACSELRAD, H. Vigiar e unir - a agenda da sustentabilidade urbana? Revista VeraCidade, ano 2, n. 2, p. 1-11, jul. 2007.

ACSELRAD, H. Sentidos da sustentabilidade urbana. In: (Org.). A duração das cidades: sustentabilidade e risco nas políticas públicas. 2. ed. Rio de Janeiro: Lamparina, 2009, p. 43-70.

ACSELRAD, H.; LEROY, J. P. Novas premissas da sustentabilidade democrática. Rio de Janeiro: BSD/ FASE, 1999. 70 p. (Série Cadernos de Debate, 1).

BAUMAN, Z. Globalização: as conseqüências humanas. Rio de Janeiro: Jorge Zahar, 1999. 145 p.

BAUMAN, Z. Tempos líquidos. Rio de Janeiro: Jorge Zahar, 2007. 119 p.

BECKER, B. K. A geopolítica na virada do milênio: logística e desenvolvimento sustentável. In: CASTRO, I. E. de; GOMES, P. C. C.; CORREAA, R. L. (Org.). Geografia: conceitos e temas. 11. ed. Rio de Janeiro: Bertrand Brasil, 2008, p. 271-307. 
BRAND, P.; THOMAS, M. J. Urban environmentalism: global change and the mediation of local conflict. London: Routledge, 2005. 237 p. (Series Contents, 10).

CALDEIRA, T. P. R. Cidade de muros: crime, segregação e cidadania em São Paulo. São Paulo: EDUSP, 2000. 400 p.

CARLOS, A. F. A. O espaço urbano: novos escritos sobre a cidade. São Paulo: Contexto, 2004. 154 p.

CASTELLS, M. A sociedade em rede. 11. ed. São Paulo: Paz e Terra, 1999. 698 p.

CASTRO, I. E. de. O problema da escala. In: ; GOMES, P. C. C.; CORRÊA, R. L. (Org.). Geografia: conceitos e temas. 11. ed. Rio de Janeiro: Bertrand Brasil, 2008, p. 116-40.

COMISSÃO MUNDIAL SOBRE MEIO AMBIENTE E DESENVOLVIMENTO. Nosso futuro comum.

2. ed. Rio de Janeiro: Ed. FGV, 1991. 430 p.

CORRÊA, R. L. O espaço urbano. 4. ed. São Paulo: Ática, 2002. 94 p.

EMELIANOFF, C. A noção de cidade sustentável no contexto europeu. Rio de Janeiro: IPPUR, mar. 2003. 16 p. (Série Estudos e Debates, 42).

EUROPEAN CITIES \& TOWNS TOWARDS SUSTAINABILITY. Aalborg charter. Aalborg, May 1994. 5 p. EUROPEAN COUNCIL OF TOWN PLANNERS. Nouvelle Charte D'Athenes 1998: prescriptions pour l'aménagement des villes édictées par le Conseil Européen des Urbanistes. Brussels, Mars 1998. 16 p.

EUROPEAN COUNCIL OF TOWN PLANNERS. The New Charter of Athens 2003: the European Council of Town Planners' vision for cities in the 21st century. Lisbon, July 2003. 21 p.

FARRET, R. L. Paradigmas da estruturação do espaço residencial intra-urbano. In: ; GONZALES, S. F. N.; HOLANDA, F. R. B. de; KOHLSDORF, M. E. (Org.). O espaço da cidade: contribuição à análise urbana. São Paulo: Projeto, 1985, p. 73-90.

GOMES, P. C. C. A condição urbana. Rio de Janeiro: Bertrand Brasil, 2002. 304 p.

GUERRA, A. J. T.; CUNHA, S. B. da (Org.). Impactos ambientais urbanos no Brasil. 3. ed. Rio de Janeiro: Bertrand Brasil, 2005. 416 p.

HAESBAERT, R.; PORTO-GONÇALVES, C. W. A nova des-ordem mundial. São Paulo: Ed. UNESP, 2006. $160 \mathrm{p}$.

HARVEY, D. A justiça social e a cidade. São Paulo: Hucitec, 1980. 291 p.

HARVEY, D. Condição pós-moderna: uma pesquisa sobre as origens da mudança cultural. 12. ed. São Paulo: Loyola, 2003. 349 p.

HARVEY, D. Espaços de esperança. São Paulo: Loyola, 2004. 382 p.

LEFEBVRE, H. O direito à cidade. São Paulo: Documentos, 1969. 133 p.

LEROY, J. P.; BERTUCCI, A. A.; ACSELRAD, H.; PÁDUA, J. A.; SCHLESINGER, S.; PACHECO, T. Tudo ao mesmo tempo agora - desenvolvimento, sustentabilidade, democracia: o que isso tem a ver com você? 2. ed. Petrópolis: Vozes, 2003. 198 p.

LOJKINE, J. O estado capitalista e a questão urbana. São Paulo: Martins Fontes, 1981. 337 p.

MASSEY, D. Um sentido global do lugar. In: ARANTES, A. A. (Org.). O espaço da diferença. Campinas: Papirus, 2000, p. 176-85.

MITCHELL, W. J. E-topia: a vida urbana - mas não como a conhecemos. São Paulo: Senac, 2002. 244 p.

ORTIZ, R. Mundialização e cultura. 2. ed. São Paulo: Brasiliense, 1994. 234 p.

PORTO-GONÇALVES, C. W. A globalização da natureza e a natureza da globalização. Rio de Janeiro: Civilização Brasileira, 2006. 461 p.

SANTOS, M. A natureza do espaço. Técnica e tempo. Razão e emoção. São Paulo: Hucitec, 1996. 308 p.

SANTOS, M. Por uma outra globalização: do pensamento único à consciência universal. 9. ed. Rio de Janeiro: Record, 2002. 174 p.

SEN, A. Development as freedom. Nova York: Knopf, 1999. 366 p. 
SINGER, P. O uso do solo urbano na economia capitalista. Boletim Paulista de Geografia, n. 57, p. 77-92, 1980.

SMITH, N. Desenvolvimento desigual: natureza, capital e a produção do espaço. Rio de Janeiro: Bertrand Brasil, 1988. 250 p.

SOJA, E. W. Geografias pós-modernas: a reafirmação do espaço na teoria social. Rio de Janeiro: Jorge Zahar, 1993. $324 \mathrm{p}$.

SPOSITO, M. E. B. O chão em pedaços: urbanização, economia e cidades no estado de São Paulo. 2004. 508 f. Tese (Livre-Docência em Geografia) - Faculdade de Ciências e Tecnologia, Universidade Estadual Paulista, Presidente Prudente, 2004.

TEODORO, P. H. M. Sustentabilidade urbana: sofisma, polissemia e utopia. Presidente Prudente, 2010. 387 p. (Relatório final FAPESP).

UNITED NATIONS. Department of Economic and Social Affairs. Population Division. World population prospects: the 2009 revision. New York, 2009. Disponível em: <http://esa.un.org/wup2009/unup/>. Acesso em: 25 jan. 2011.

Trabalho enviado em dezembro de 2011

Trabalho aceito em janeiro de 2012 